\title{
NEUROCIÊNCIA COGNITIVA E METODOLOGIAS ATIVAS
}

\author{
Magda Schmidt Brasil ${ }^{1}$
}

RESUMO: A neurociência estuda o Sistema Nervoso e o cérebro com suas complexas estruturas mentais. Compreender como funcionam os processos cognitivos a partir da neurociência tornou-se um desafio para os profissionais da educação. O presente artigo tem a intenção de elucidar como a neurociência contribui para a educação e de que maneira as Metodologias Ativas podem facilitar a trajetória para o desenvolvimento cognitivo, visto que a multiplicidade do cérebro tem a capacidade de traçar rotas alternativas, a fim de adaptar o conhecimento, torna-se necessário investigar os métodos de ensino mais adequados. A aprendizagem está relacionada com as estruturas mentais e a neuroplasticidade cerebral que possibilita transformações a cada novo estímulo ou a cada nova informação. As Metodologias Ativas (MA) são estratégias com inúmeras possibilidades para o processo de aprendizagem. O principal objetivo da MA é impulsionar o estudante ao protagonismo, nesse sentido o sujeito aprendente é o centro do processo com capacidade de construir seu próprio conhecimento, de acordo com a neurociência essa é a estratégia mais favorável para estimular e armazenar o conhecimento. A MA não é uma descoberta recente, iniciou da década de 40 e expandiu ganhando visibilidade a partir dos avanços tecnológicos e da evolução da web. A pergunta que fica para ser respondida no percurso dessa pesquisa, concerne a maneira que as Metodologias Ativas podem contribuir para a educação a partir dos estudos da neurociência cognitiva.

PALAVRAS-CHAVE: Neurociência cognitiva. Metodologias Ativas. Protagonismo.

\section{INTRODUÇÃO}

O termo neurociência surgiu em 1970, mas os estudos sobre o cérebro existem desde a Grécia Antiga, recentemente os neurocientistas conseguiram mapear o cérebro realizando descobertas significativas graças a tecnologia, a neurociência explica como funciona o cérebro e suas conexões neurais no processo cognitivo, explica os fatores que provocam as dificuldades e os transtornos de aprendizagem, bem como os distúrbios neurocognitivos.

\footnotetext{
${ }^{1}$ Mestranda em Educação pela Universidade Internacional Iberoamericana. Porto Rico. Pós-Graduada em Neuropsicopedagogia clínica. Graduada em Pedagogia pela ULBRA, P. Já atuou como professora de rede privada e como supervisora pedagógica na rede pública da cidade de Esteio no RS. https://orcid.org/ooooooo3-0659-843X. E-mail: magda.brasil@gmail.com.
} 
Com exceção da deficiência intelectual o ser humano nasce com potencial inteligível, porém no percurso da vida alguns adventos vão bloqueando os canais por onde passa a aprendizagem provocando a defasagem. A genética influencia muito no desenvolvimento humano e nos processos cognitivos, mas o indivíduo também é resultado do meio ambiente em que vive e suas experiências. Alguns episódios traumáticos no decorrer da vida de cada sujeito deixam sequelas que exigem um trabalho multidisciplinar, nesses casos nada mais apropriado que uma intervenção neuroeducacional, campo que nasceu da relação entre neurociência cognitiva, psicologia e educação.

Considerando que o comportamento humano é complexo e abrange sistemas distintos como aspectos cognitivos, emocionais e ação autorreguladora, a neuroeducação depende das diferentes áreas do conhecimento para desenvolver um trabalho minucioso do ponto de vista psicológico, neurológico e pedagógico. Analisar o indivíduo como um sujeito integral nas dimensões de ordem social, emocional, intelectual e física é função da equipe neuroeducadora, podendo a mesma amparar a pedagogia e a psicopedagogia que respondem pelas questões cognitivas diariamente no contexto educacional. A prática de intervir, redirecionar o processo de aprendizagem e ajustar a mudança de comportamento quando necessário é um desafio no cotidiano escolar, por esses motivos torna-se imprescindível conhecer pelo menos os conceitos básicos da neurociência.

A aprendizagem pode ou não se consolidar a partir das conexões neurais, assim, podemos compreender melhor as dificuldades e os comportamentos inadequados ou desviantes. Quando não acontece a passagem da informação que deve ser liberada a partir de um neurotransmissor (substâncias químicas) é possível reiniciar a aprendizagem fazendo um novo caminho e é aqui que iniciamos abordagem das Metodologias Ativas (MA).

Ao mesmo tempo em que a neurociência explica o desenvolvimento cognitivo, também dialoga com a aprendizagem ativa e consequentemente com a MA, nesse movimento dialógico o estudante desempenha um papel ativo frente a uma proposta pedagógica inovadora, a postura de autoria e protagonismo do sujeito aprendente pode alterar uma aprendizagem ou um comportamento já instalado. 
Essa pesquisa tem uma sistemática bibliográfica, qualitativa e descritiva utilizando três palavras chave: neurociência cognitiva, metodologias ativas e protagonismo. O estado da questão tem como base os estudos na especialização de "Metodologias Ativas" realizado na instituição UNINASSAU, pelos textos do curso " Neuropsicopedagogia Clínica" da FAVENI, busca de artigos e livros digitais em site acadêmicos. As fontes mais utilizadas para referência abrangem Consenza; Guerra (2011) e Rodrigues (2018) com enfoque nos dois campos, neurociência cognitiva e Metodologias Ativas.

A hipótese central desse trabalho tem em vista confirmar se a neurociência cognitiva pode facilitar o desenvolvimento dos processos cognitivos considerando as MA como estratégias em sala de aula.

No que se refere aos objetivos da investigação, vale frisar novamente a convergência entre neurociência e aprendizagem ativa que se complementam, além disso, também é importante refletir sobre alguns fatores que vêm ressignificando as práticas pedagógicas como o papel do educador, compreender como funciona os processos cognitivos a partir do funcionamento biológico do cérebro e analisar os métodos de ensino mais adequados para promover uma aprendizagem significativa. Como tudo começa na mente humana, a emoção, a atenção e a memória são fatores de muita relevância no contexto pedagógico, o educador precisa considerar a importância de refletir, planejar e atuar com estratégias dinâmicas a fim de mobilizar o estudante no sentido de aprender a aprender. $O$ aluno que atua ativamente a partir da metodologia proposta consegue desenvolver a habilidade de transformar a relação com o conhecimento e adquirir as competências necessárias.

No mundo contemporâneo encontramos o grande desafio de buscar um equilíbrio entre os imigrantes digitais (professores) e os nativos digitais (alunos). Os educadores estão se reinventando enquanto os estudantes estão se adaptando a uma realidade no qual deixam de ser alunos para serem estudantes. Nesse mundo da relatividade, as respostas não são mais lineares e as informações estão cada vez mais fluidas, é fato que as distrações podem prejudicar o estudante que acaba direcionando o foco para questões de seu próprio 
interesse, como o smartphone por exemplo e nesse viés a neurociência também aborda a importância de considerar esses interesses.

Assim, esse artigo pretende discorrer as contribuições da neurociência para a educação e a relação entre neurociência e aprendizagem ativa, para chegar à compreensão da aprendizagem ativa na prática, vamos dialogar sobre os diferentes recursos e ferramentas que norteiam as MA.

\section{CONTRIBUIÇÃO DA NEUROCIÊNCIA PARA A EDUCAÇÃO}

Visto que neurociência estuda o SNC e circunda nas diferentes áreas do conhecimento como medicina, psicologia e pedagogia percebemos a relevância do assunto, se tratando de educação nosso foco fica restrito a neurocognição. A neurociência leva para o contexto educacional alguns conceitos importantes que colaboram com as práticas pedagógicas, conceitos sobre memória, atenção, emoções, afetividade, estímulos, ambiente, repetição, tempo e sono.

O córtex pré-frontal é responsável pela atenção, o hipocampo se encarrega das memórias e o sistema límbico pelas emoções, as amígdalas também têm a função de identificar a emoção. Esses três princípios norteiam o desenvolvimento cognitivo, sendo que a afetividade também exerce uma forte influência nesse processo. A atenção possibilita um período de concentração que pode ou não reter a informação na memória. É necessário perceber que as vezes o tempo de concentração é curto, por isso, o período de sono também é considerado fundamental, enquanto dormimos os neurônios fazem as conexões necessárias para organizar a aprendizagem.

\footnotetext{
Existem pelo menos três circuitos nervosos importantes para o fenômeno da atenção. O primeiro mantém os níveis de vigilância ou alerta. O segundo é o orientador e desliga o foco de atenção de um ponto e dirige-o em outro sentido, permitindo ainda uma maior discriminação do item a ser observado. O terceiro é o circuito executivo, que mantém a atenção e inibe os distraidores até que o objetivo seja alcançado. (CONSENZA; GUERRA, 2oır, p. 49).
}

A memória pode ser de curto ou longo prazo, a de curto prazo é estimulada pelos sentidos, principalmente audição e visão, normalmente essa memória curta busca um ponto de ancoragem no cérebro para armazenar a nova informação na memória de longo 
prazo, por esse motivo os conhecimentos prévios dos alunos são importantes para o processo cognitivo. Essa teoria foi elaborada por Ausubel (1963), é muito conhecida como Aprendizagem Significativa, o cérebro precisa reconhecer o significado pois ele seleciona as informações mais importantes e descarta conteúdos descontextualizados. Nessa mesma linha Flavell (1976) também explica o conceito de metacognição que é a habilidade de autorregulação da aprendizagem.

Conforme a informação é captada pelo foco da atenção a aprendizagem se consolida, a memória em curto prazo pode ser esquecida quando não encontra uma ligação, porém o cérebro tem a capacidade de buscar conexão através dos neurônios. "As sinapses, portanto, são os locais que regulam a passagem de informações no sistema nervoso e, como veremos, têm uma importância fundamental na aprendizagem". (CONSENZA; GUERRA, 20II, p. II).

No desenvolvimento cognitivo a plasticidade cerebral tem a função de acomodar o conhecimento conforme o cérebro vai se transformando e adaptando a aprendizagem, a partir de um novo estímulo. A estimulação ambiental e as interações sociais impulsionam o funcionamento do cérebro no que se refere a neuroplasticidade, pois a mesma permite conexões sinápticas que perduram por toda vida do ser humano com capacidade de modificar comportamentos. De acordo com Relvas (2015, n.p): "Pode-se imaginar o desenvolvimento como um cenário onde vários feixes de luz (cada função química cognitiva ou afetiva) se entrelaçam, mesclando-se, e, quando um se adapta, o todo se modifica, desarmonizando o cenário".

Os estudos da neurociência têm muito a contribuir, para psicopedagogia, psicologia, neuroeducação e principalmente para a pedagogia, sabendo que as dificuldades e transtornos vão surgindo com a interferência ambiental é indispensável investigar quais as metodologias mais adequadas para realizar as intervenções pedagógicas.

A aprendizagem eficaz e o comportamento adequado dependem de funções executivas ajustadas o que nem sempre é possível em virtude das lesões cerebrais e traumas sofridos durante a vida, por essa razão a condição emocional e a afetividade influenciam tanto na aprendizagem. O cérebro pode se regenerar através da plasticidade, 
podemos dizer que emoção e afeto estão intimamente relacionados com a cognição. $\mathrm{O}$ afeto é um estado emocional que implica sentimentos que causam mudanças no corpo e na mente. Para os psicólogos Piaget, Wallon e Vygotsky, a afetividade e inteligência podem fundamentar o desenvolvimento mental. As teóricas psicogenéticas defendem ideias sob ângulos diferentes, mas trouxeram grande contribuição para a pedagogia e a psicologia. (LA TAILLE; OLIVEIRA; DANTAS, 1992).

A anatomia do cérebro humano se divide em cinco partes: lobo frontal; temporal; parietal; occipital; e insular, essa estrutura cerebral possibilita múltiplas eficiências que completa o sujeito como ser individual, social, cérebro motor, cérebro criativo e genial e por último cérebro afetivo emocional, que organiza e equilibra as emoções determinando o comportamento humano e seu desenvolvimento. Parafraseando Vygotsky (COLE et al., I99I), no enfoque sociointeracionista a aprendizagem e o desenvolvimento acontecem de forma indissociável. Ao mesmo tempo em que o cérebro aprende; ele também se desenvolve.

A dificuldade pode surgir de uma emoção negativa que provavelmente vai bloquear a aprendizagem impedindo a elaboração cognitiva, a afetividade é um fator determinante para ativar a cognição novamente, por isso o ambiente escolar deve ser um lugar saudável, seguro e acolhedor para favorecer a maturidade emocional. A maturidade inicia no nascimento e passa por quatro estágios, começa no sensório motor e segue pelo préoperatório; operatório concreto e continua se desenvolvendo até o estágio operatório formal. No último estágio a partir dos onze anos, o aluno já compreende conceitos abstratos. (PIAGET, 1974).

Uma das competências necessárias para o século XXI é a inteligência emocional estudada por Goleman (1995), essa teoria se distancia da inteligência tradicional que se baseia apenas no QI, a inteligência emocional é uma habilidade de administrar as emoções e controlar os impulsos, isso implica autoconhecimento e significa amadurecimento mental que potencializa a capacidade inteligível. Compreendendo que atenção, memória, emoções e afetividade estão interligadas no processo de cognição, podemos entender melhor porque a neurociência é importante para a educação. 
As neurociências descrevem a estrutura e o funcionamento do sistema nervoso, enquanto a educação cria condições que promovem o desenvolvimento de competências. Os professores atuam como agentes nas mudanças cerebrais que levam à aprendizagem. (COCH; ANSARI, 2009, p. 546-547).

Além da atuação do professor, a família também deve ter um papel ativo, a presença dos pais ou responsáveis faz a diferença para o desenvolvimento cognitivo do aluno. A família deve funcionar como um termômetro que sinaliza para os educadores qualquer evento fora do normal que possa desestabilizar emocionalmente a criança ou adolescente, a parceria entre família e escola favorece os procedimentos da psicopedagogia e da neuroeducação.

Em algumas ocasiões a dificuldade de aprendizagem pode ser transitória porque é gerada por um desiquilíbrio emocional temporário, porém existem casos mais graves de deficiências, transtornos ou doenças neurológicas, para essas circunstâncias o aluno e a família podem contar com uma estrutura escolar diferenciada chamado de Plano Pedagógico Especializado, nesse contexto o aluno tem o direito de ser atendido por um profissional da educação especial e frequentar um espaço chamado Sala de Recursos Multifuncional. O APE tem a finalidade de elaborar uma adaptação curricular que garanta ao aluno uma inclusão justa, igualitária e personalizada, todo esse suporte tem base na legislação brasileira Decreto n. 6.57I/o8. (FAVENI, 2020, p. 35-36).

Apesar de a inclusão escolar caminhar a passos lentos se percebe um esforço das políticas públicas para uma educação inclusiva, essa preocupação passou a existir depois da Declaração de Salamanca na Espanha em 1994. (FAVENI, 2020, p. 50).

\section{NEUROCIÊNCIA E APRENDIZAGEM ATIVA}

A formação biológica do cérebro, suas transformações e as inteligências dependem de uma construção ativa que só é possível à medida que acontecem as interações. As interações acontecem a partir do engajamento e da colaboração entre estudantes com seus pares e estudante com seu tutor. A aprendizagem ativa é essencial para conectar os labirintos da memória e desenvolver as inteligências.

Segundo Mazur (2015, p. o8): 
[...] é muito pouco o que se aprende em uma aula expositiva passiva, enfatizando que um professor não consegue simplesmente jogar o conhecimento em suas mentes. Não importa o quão bom um professor é, pois é aos estudantes que cabe esse trabalho.

Alguns estudos comprovam que o cérebro é incrivelmente inteligente o que acaba sendo uma vantagem para os educadores, contudo o desafio de mobilizar o aluno para aprender a aprender precisa ser uma constante, o ambiente de aprendizagem deve estimular os aprendentes gerando empatia e afinidades.

A neurociência aponta alguns fatores importantes para o funcionamento do cérebro, além do estímulo, motivação, emoções e afetividade; é importante observar, curiosidade, repetição, tempo de aula, ambiente, participação e avaliação.

O educador precisa estar atento, observar o estudante, seus interesses e curiosidades, repetir as informações de maneira criativa para reativar os circuitos neurais, planejar considerando que o tempo de concentração não é longo, propiciar um ambiente favorável para a aprendizagem e compreender a avaliação como uma estratégia que redireciona as práticas pedagógicas. As intervenções pedagógicas e o feedback positivo ajudam o aluno a desenvolver uma relação de prazer com a aprendizagem mantendo-o motivado. A motivação é um fator intrínseco e fundamental no contexto educacional, quando bem aplicados, os métodos ativos possibilitam uma atmosfera favorável para uma aprendizagem que motiva todos os envolvidos.

Já constatamos que o aluno não é um mero receptor, a avaliação diagnóstica é uma estratégia para considerar os conhecimentos prévios e mediar o processo numa perspectiva de protagonismo e autoria do estudante na construção de seu conhecimento.

Ao mencionar a repetição como aliada da neurociência e da aprendizagem é necessário enfatizar que as metodologias ativas tendem a promover o ato de repetir a mesma informação de diferentes formas para atingir os objetivos de aprendizagem.

Nesse processo, observamos a repetição do uso da informação, juntamente com sua elaboração, ou seja, sua associação com os registros já existentes, o que fortalece o traço de memória e o torna mais durável. Quantas vezes mais se 
repetir essa atividade, o quanto mais ligações ou "ganchos" forem estabelecidos com informações disponíveis no cérebro, melhor será, pois, o registro vai se fixar de forma mais permanente. (CONSENZA; GUERRA, 2oIr, p. 62).

A aprendizagem ativa se baseia em alguns princípios, são eles: aluno como protagonista; aprendizagem autônoma; prática reflexiva; resolução de problemas; atividades colaborativas; e professor como orientador, esses aspectos colaboram ativamente para o desenvolvimento do cérebro. (RODRIGUES, 2018).

Nessa concepção o aluno precisa estar no centro do processo e a aprendizagem não pode ser fora de contexto, o cérebro não reconhece a informação descontextualizada porque não tem significado.

Para a aprendizagem ativa se torne inovadora é preciso uma mudança de mentalidade de todos, instituição, família, alunos e educadores, mas principalmente dos educadores. O paradigma conservador, a reprodução do ensino e a formação do sujeito passivo não se encaixam mais em nossa realidade contemporânea. Observar para onde a educação está se encaminhando é urgente, o aluno do presente e do futuro precisa desenvolver algumas habilidades como resiliência, criatividade e inteligência emocional, cada vez mais se exige uma performance autodidata.

O estudante precisa interagir de diferentes formas, assumindo a autoria do seu processo cognitivo, não somente ouvindo, vendo ou falando, mas também dialogando, fazendo e ensinando. A teoria da Pirâmide da Aprendizagem de Wiliam Glasser (19252013), psiquiatra americano, defende que o menor índice de aprendizagem ocorre quando lemos, escutamos, vemos e ouvimos e os maiores índices de aquisição cognitiva ocorrem, quando discutimos com os outros, quando fazemos e quando ensinamos, por isso o papel ativo do aluno favorece o desenvolvimento e o papel do professor também é ressignificado, porque ele passa a ser o guia do aluno nesse processo.

É fato que a realidade complexa desse século se inclina para uma educação inovadora, toda prática educacional precisa de uma base filosófica, por isso a formação contínua e fundamental, principalmente quando falamos de tecnologia digital que veio para ficar e pode facilitar a aplicação das Metodologias Ativas, a combinação de tecnologia com metodologia adequada pode trazer grandes benefícios. 


\section{METODOLOGIAS ATIVAS}

A MA surgiu na década de 1940 no Reino Unido com o inglês Reg Revans num contexto industrial e foi adaptada para a realidade educacional, a escola hoje se utiliza dessas técnicas de ensino para potencializar as inteligências necessárias para esse tempo (SANTOS, 2019, p. 7). Os diferentes métodos ativos não precisam ser obrigatoriamente tecnológicos, todavia é importante prestar atenção que as mídias digitais vêm ganhando espaço numa velocidade gigantesca.

Antes de iniciar apontando os benefícios da MA devemos observar a fragilidade de alguns pontos, a tecnologia digital e o avanço da web 4.0 vieram para colaborar, porém as informações estão cada vez mais fluidas, é fato que as distrações podem prejudicar o estudante que acaba perdendo o foco, nesse contexto destacamos o papel do educador que precisa ter bem claro a intencionalidade pedagógica para conduzir a aprendizagem. $\mathrm{O}$ estudante precisa ser orientado pelo educador e assim desenvolver a habilidade de filtrar todas as informações numa postura crítica e reflexiva. Desmitificar o preconceito que existe sobre a tecnologia digital em sala de aula também é uma problemática, porque alguns educadores ainda não conseguem perceber a tecnologia como uma ferramenta para ser utilizada a favor de todos. Apesar desses pontos frágeis algumas pesquisas apontam a eficácia da MA para o processo educacional no contexto escolar.

As metodologias ativas podem e devem ser vistas como um benefício para a prática do professor. Muito mais do que apenas trabalhar com os conteúdos previamente estabelecidos no currículo das disciplinas, as metodologias ativas auxiliam o educador a desenvolver a autonomia e a curiosidade dos seus alunos. (RODRIGUES, 2018, p. 13).

Importante lembrar que esses métodos ou técnicas diferenciadas também podem ser utilizadas pelos psicopedagogos, psicólogos e outros profissionais que façam parte da equipe neuroeducadora.

Sabemos que a MA pode ser analógica e não exige necessariamente as tecnologias digitais, mas também é notório que essa geração atual e a geração vindoura o qual chamamos de nativos digitais é totalmente conectada, isso significa que todo o interesse deles se volta cada dia mais para essa dimensão futurista. 
Segundo a professora especialista em tecnologias digitais Martha Gabriel (2013, p. I08):

\begin{abstract}
A internet traz interatividade entre as pessoas conectadas, permitindo troca de experiências e discussões centradas no interesse do estudante. Assim, independentemente da vontade, ciência ou permissão dos professores, os estudantes resgatam para si a interatividade e foco da aprendizagem por meio das tecnologias digitais $[\ldots]$.
\end{abstract}

Logo após definir os objetivos de aprendizagem é interessante pensar qual o melhor recurso para o público-alvo (vídeos, imagens, áudios, simuladores). O planejamento da ferramenta também é indispensável, pois existe inúmeras possibilidades como aplicativos, blogs, chats, fórum e redes sociais. Os estudantes precisam compreender que o trabalho em equipe e a interação colaborativa é fundamental nas MA.

Considerando que cada estudante aprende de um jeito diferente o educador deve pensar em métodos variados de acordo com a necessidade. O ser humano se desenvolve em sua totalidade e podemos utilizar os métodos ativos para propiciar uma formação integral.

Nessa mesma linha de pensamento e ainda valorizando as diferentes formas do aprender, também podemos mencionar as Inteligências Múltiplas, no contexto escolar. Parafraseando Gardner (psicólogo) existe uma tendência em priorizar a matemática e a linguagem, o que prejudica muito os estudantes, principalmente quando se trata de avaliação, as inteligências se dividem em diferentes partes com o mesmo grau de importância. São elas: lógica, linguística, naturalista, cinestésica, musical, espacial, interpessoal e intrapessoal. De acordo com essa teoria o cérebro é constituído por essas peças que podem se desenvolver mais ou menos, dependendo da individualidade de cada sujeito e dos estímulos que ele recebe. (GARDNER, 1983).

Como é possível desenvolver as inteligências no contexto escolar? As Inteligências Múltiplas devem permear o currículo tornando-o cada vez mais um organismo vivo. É possível criar possibilidades e inovar buscando estratégias que fogem da concepção tradicional.

Procurando por aplicações práticas e criativas, Bruce Campbell direcionou diferentes experiências em várias escolas da zona de Seattle, nos Estados Unidos. Campbell projetou diferentes espaços dedicados a cada inteligência, para os quais foram utilizados espaços de toda escola ou cantos dentro de cada sala de aula. Esses espaços, "espaços inteligentes", animaram tanto alunos como professores para compreender o conteúdo do currículo com atividades, materiais e exercícios próprios do potencial de cada uma das inteligências. (HERNANDO, 2016, p. 38). 
No Brasil já existe essa prática na Educação Infantil, que visa atender as exigências da última versão da Base Nacional Comum Curricular (BNCC), ficou documentado na BNCC a importância de considerar os direitos das crianças, sendo que um deles é o direito de escolha. O direito de escolha faz muito sentido, visto que já falamos sobre observar o interesse de cada aluno para a aprendizagem.

Partimos do pressuposto que a neurociência pode contribuir muito com a educação enquanto a MA é o meio para facilitar o desenvolvimento cognitivo, sendo assim, lembramos que essas metodologias se baseiam nos princípios de protagonismo, autonomia, prática reflexiva, resolução de problemas, atividades colaborativas e professor/orientador.

O protagonismo se refere a participação do aluno, sendo ele o centro do processo, na autonomia o aluno consegue gerir sua aprendizagem com liberdade para conduzir da maneira que ele entende ser mais produtivo, na prática reflexiva é o educador que estimula os estudantes promovendo espaços de diálogos e troca de experiências, na resolução de problemas desenvolve-se a habilidade de aplicar a teoria na prática trazendo sentido para aprendizagem; e na atividade colaborativa aprende-se a fazer e conviver compartilhando saberes, quanto ao papel do professor/orientador podemos dizer que, ele passa a ser um colaborador que facilita o processo ao mesmo tempo que busca formação para qualificar sua prática pedagógica.

São inúmeras as estratégias que promovem dinamismo colocando o estudante numa posição ativa ou participativa. Vamos falar de algumas e iniciar com aquela que está muito relacionada com a neurociência porque nos lembra as conexões neurais no processo cognitivo, Mapas Mentais e Conceituais.

O Mapa Mental parte de uma ideia ou tema central e a partir dela se ramifica com ideias secundárias inter-relacionadas, o objetivo é encadear o pensamento acomodando novos conhecimentos de forma conectada. $\mathrm{O}$ mapa conceitual segue na mesma lógica, os conectores interligam os conceitos formando uma rede de informações. Nessa metodologia o principal objetivo é colocar o aluno para construir seu gráfico organizando as ideias, 
chamamos de Mapa Mental Invertido, porque é o aluno que desenvolve o mapa enquanto o professor apenas orienta. (QUEIROZ, 2019, p. 4).

A Sala de Aula Invertida é um método bem comum e bastante utilizado e não pode ser confundido com tarefa de casa, o educador escolhe uma ferramenta para enviar o conteúdo (texto, vídeo, podcast) enquanto o estudante se apropria do mesmo levando as dúvidas para debater em sala de aula. Essa estratégia ajuda a ganhar mais tempo para diálogos e troca de ideias em sala. (BERGMANN; SAMS, 2016).

No Estudo de Caso o aluno é colocado frente a um problema real ou fictício, para investigar a melhor maneira de resolvê-lo, esse método fomenta a pesquisa e estimula o trabalho em equipe. Semelhante ao Estudo de Caso também temos a Aprendizagem Baseada em Projetos e a Aprendizagem Baseada em Problemas, esses três métodos são diferentes um do outro, mas todos exigem pesquisas e resolução de problemas.

O Ensino Híbrido é uma mistura entre Ensino a Distância e Ensino Presencial, geralmente se utiliza aplicativos para iniciar a aprendizagem a distância para dinamizar os processos em sala de aula, a estratégia para o momento presencial chama-se Rotação por Estações onde é organizado um circuito de atividades, uma diferente da outra para estudar o mesmo assunto, os alunos precisam passar por todas as estações que normalmente variam entre produção textual, pesquisa na internet, construção de cartazes e apresentação do trabalho em grupo.

Existem outras estratégias interessantes como: Gamificação; Simulação, Robótica; Aprendizagem Maker; Júri Simulado; Ensino com pesquisa; Aula Dialogada; entre outros que estão surgindo.

Para escolha de metodologias mais assertivas é necessário planejamento, se utilizar da tecnologia aleatoriamente não promove aprendizagem, a intenção pedagógica é o carro chefe da MA. Também é importante aplicar a avaliação diagnóstica para conhecer os alunos no que se refere aos conhecimentos já adquiridos. As plataformas de ensino e os aplicativos podem facilitar a avaliação diagnóstica e se beneficiar das interfaces promovendo um espaço de comunicação onde todo o grupo pode expressar seu ponto de vista a respeito de um conteúdo antes mesmo dele ser estudado. $O$ fórum, chats, blogs e 
outros são grandes aliados nesse sentido. Além desses recursos também é possível utilizar plataformas e aplicativos que auxiliam na personalização do ensino, pois à medida que o aluno avança o educador acompanha e orienta preenchendo lacunas em seu processo de estudo, isso é possível porque a ferramenta fornece ao educador dados que apontam as dificuldades. De acordo com Lilian Bacich, da Tríade Educacional, plataformas adaptativas e recursos digitais potencializam o ensino personalizado. "São recursos a mais que apoiam o professor, oferecendo-lhe dados de uma maneira muito mais rápida [...]”, afirma a especialista convidada pelo CIEB para comentar a websérie. (BACICH, 2020, n.p).

Todos os métodos mencionados acima, inclusive a elaboração de percursos personalizados pode potencializar o processo cognitivos da mente. Podemos considerar, que essas práticas pedagógicas (métodos) estão alinhadas com a neurociência que foca a aprendizagem numa perspectiva de construção ativa do cérebro.

\section{CONCLUSÃO}

A neurociência cognitiva nos fornece uma base teórica bem sólida sobre o potencial do cérebro humano a partir das aprendizagens ativas, o déficit cognitivo pode ser de ordem genética, mas os casos de dificuldades de aprendizagem ocorrem em virtude da ausência de estímulos, sendo assim, a MA acaba sendo o meio pelo qual essa aprendizagem ativa é possível. A maneira que o cérebro processa as informações nos remete a reflexão sobre alguns conceitos da neurocognição que estão interconectados diretamente com às práticas pedagógicas. A metodologia e a avaliação nos processos cognitivos podem promover resultados efetivos, para o planejamento desses dois momentos deve-se considerar as inteligências múltiplas e a aprendizagem significativa.

Esses conceitos básicos de estímulos, motivação, memórias, sentimentos, raciocínio entre outros elementos precisam ser analisados cuidadosamente no contexto educacional com o objetivo de ressignificar a prática do educador. Sabemos que, as atividades cerebrais influenciam no comportamento do estudante e que esse mesmo comportamento pode ser modificado através da neuroplasticidade, pois podem refazer as conexões neurais transformando as aprendizagens. Essa dinâmica da neurocognição acontece ao longo de 
toda vida do ser humano lembrando que, utilizamos I0o\% de nosso cérebro e ele nunca desliga, quando dormimos as sinapses entram em ação e os neurônios fazem conexões a partir das informações processadas durante o dia.

Alinhadas, Aprendizagem Ativa e a Neurociência Cognitiva confirmam a importância dos estímulos do meio ambiente que podem dinamizar todo processamento, sendo assim o papel do educador torna-se uma busca constante para alcançar os objetivos de aprendizagem, assumir uma postura de aprendiz e ao mesmo tempo de mentor/facilitador no processo de desenvolvimento do educando é inevitável. Nesse panorama acima descrito, aprender a aprender também é uma tarefa para todos os envolvidos no processo, a necessidade de formação continuada é muito pertinente e nos impulsiona a pensar urgentemente, mas deixaremos para refletir sobre esse assunto em outro momento.

Os estudos sobre Neurociência Cognitiva e Metodologias Ativas continuam a reverberar, mas podemos inferir que a hipótese inicial do trabalho em verificar a eficácia da MA considerando a importância de alguns estudos e conceitos da neurociência cognitiva faz muito sentido para os processos e possibilita muitos benefícios, desde que se observe os seis princípios necessários para o processo, sempre mediando os pontos frágeis durante o percurso.

\section{REFERÊNCIAS BIBLIOGRÁFICAS}

AUSUBEL, D. P. The psychology of meaningful verbal learning. New York: Grune and Stratton, 1963.

BACICH, Lilian. A potência do ensino personalizado para apoiar a prática pedagógica inovadora. 13 fev. 2020. CIEB - Notícias Gerais. Disponível em: $\langle$ https://cieb.net.br/apotencia-do-ensino-personalizado-para-apoiar-a-pratica-pedagogica-inovadora/>. Acesso em: II set. 2020.

BERGMANN, Jonathan; SAMS, Aaron. Sala de aula invertida: uma metodologia ativa de aprendizagem. Rio de Janeiro: LTC, 2016. 
$\mathrm{COCH}$, D.; ANSARI, D. Thinking about mechanisms is crucial to connecting neuroscience and education. Cortex, v. 45, n. 4, p. 546-547, 2009.

COLE, M.; JOHN-STEINER, V.; SCRIBNER, S.; SOUBERMAN, E. A formação social da mente. Vygotsky, L. S. Tradução José Cipolla Neto, Luis Silveira Menna Barreto, Solange Castro Afeche. 4. ed. São Paulo: Martins Fontes, 199ı.

CONSENZA, Ramon; GUERRA, Leonor. Neurociência e educação: como o cérebro aprende. Porto Alegre: Artmed, 2011.

FAVENI. Adaptações curriculares para a educação inclusiva. Maceió: FAVENI, 2020.

FLAVELL, J. H. Metacognitive aspects of problem solving. In: RESNICK, L. B. (org.).

The nature of intelligence. Hillsdale, New York: Erlbaum, 1976. p. 231-235.

GABRIEL, Martha. Educar: a revolução digital na educação.ı. ed. São Paulo: Saraiva, 2013.

GARDNER, Howard. Frames of mind: the theory of multiple intelligences. New York: Basic Books, 1983.

GOLEMAN, D. Inteligência emocional. Rio de Janeiro: Objetiva, 1995.

HERNANDE, Alfredo Calvo. Viagem à escola do século XXI: assim trabalham os colégios mais inovadores do mundo. ı. ed. São Paulo: Fundação Telefônica Vivo, 2016.

LA TAIlle, Yves de; OliVeirA, Marta Kohl de; DANTAS, Heloysa. Piaget, Vygotsky, Wallon: teorias psicogenéticas em discussão. São Paulo: Summus, 2016.

MAZUR, E. Peer instruction: a revolução da aprendizagem ativa. I. ed. Porto Alegre: Penso, 2015.

PIAGET, J. A tomada de consciência. São Paulo: EDUSP/Melhoramentos, 1974.

QUEIROZ, Andressa Ribeiro de. Gráficos, painéis mapas e conceitos e mentais: unidade 3. Recife: Grupo Ser Educacional, 2019.

RELVAS, Marta. Neurociência e transtornos de aprendizagem. 6. ed. Rio de Janeiro, 2015. E-Book.

RODRIGUES, Amanda. Metodologias ativas. São Paulo: IGM, 2018.

SANTOS, Andréa Cesar Pedrosa da Silva. Metodologias ativas: unidade 2. Recife: Grupo Ser Educacional, 2019. 